\title{
Continuity of Care: Is the Personal Doctor Still Important? A Survey of General Practitioners and Family Physicians in England and Wales, the United States, and the Netherlands
}

Tim Stokes, $\mathrm{PbD}, \mathrm{MPH}, \mathrm{MBCbB^{1 }}$

Carolyn Tarrant, $\mathrm{BSc}^{1}$

Arch G. Mainous III, $\mathrm{PbD}^{2}$

Henk Schers, MSc, MD

George Freeman, $M D^{4}$

Richard Baker, $M D^{1}$

'Department of Health Sciences, University of Leicester, Leicester, UK

${ }^{2}$ Department of Family Medicine,Medical University of South Carolina, Charleston, SC

${ }^{3}$ Department of General Practice,University Medical Centre St Radboud, Nijmegen, The Netherlands

${ }^{4}$ Centre for Primary Care and Social Medicine, Imperial College, London, UK

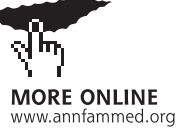

MORE ONLINE

\section{CORRESPONDING AUTHOR}

Tim Stokes, PhD

Clinical Governance Research

and Development Unit

Department of Health Sciences

Division of General Practice

and Primary Health Care

University of Leicester

Leicester General Hospital

Leicester LE5 4PW

tns2@1e.ac.uk

\begin{abstract}
PURPOSE We determined the reported value general practitioners/family physicians in 3 different health care systems place on the various types of continuity of care.

METHODS We conducted a postal questionnaire survey in England and Wales, the United States, and the Netherlands. The participants were 1,523 general practitioners/family physicians (568 from England and Wales, 453 from the United States and 502 from the Netherlands). Our main outcome measures were the perceived importance of the types of continuity of care and doctor or practice characteristics that may influence attitudes toward personal continuity of care.
\end{abstract}

RESULTS The response rates were England and Wales 60\% (568/946), United States $47 \%$ (453/963) and Netherlands 76\% (502/660). The doctors in all 3 countries felt strongly that personal continuity remained an important aspect of goodquality care to their patients. Within a given health care system, doctors' personal and practice characteristics explained only a small part of the variance in attitudes toward the provision of personal continuity of care (England and Wales and the Netherlands $r^{2}=0.04$, United States $r^{2}=0.01$ ). The doctors in all 3 countries felt that they were currently able to provide all 3 types of continuity of care, although doctors in England and Wales were least positive about the provision of informational and management continuity across the primary-secondary care divide.

CONCLUSIONS General practitioners/family physicians from 3 differing health care systems all place high value on being able to provide personal continuity of care to patients. Personal continuity of care remains a core value of general practice/ family medicine and should be taken account of by policy makers when redesigning health care systems.

Ann Fam Med 2005;3:353-359. DOI: 10.1370/afm.351.

\section{INTRODUCTION}

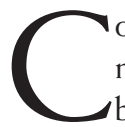
ontinuity of care is an important element of the delivery and organization of primary health care. ${ }^{1}$ It has consistently been shown to be associated with increased patient and doctor satisfaction and may positively affect other health outcomes, such as adherence to treatment, uptake of preventive services, and decreased hospitalizations..$^{2,3}$ Continuity can be understood as the degree to which a series of discrete encounters with health care clinicians is experienced as coherent, connected, and consistent with the patient's medical needs and personal context. ${ }^{4}$ Three distinct means of providing continuity have been identified: personal continuity (provision of care through an ongoing clinician-patient 
relationship), continuity of information (the use of information on past events and personal circumstances to make current care appropriate), and management continuity (a consistent and coherent approach to the management of a health problem). ${ }^{2,4}$

There has, however, been increasing concern in many countries that the changing nature of general practice/family medicine in the last 30 years has led to a reduction in the extent to which physicians can offer personal continuity despite recent research that shows patients want personal continuity from their physicians, particularly for serious conditions. ${ }^{5-8}$ Physicians have tended to reorganize themselves into large-group practices where care is delivered by members of the primary health care team; patients may themselves prefer fast access to any physician rather than wait to see a physician of their choice. ${ }^{9-11}$ In England and Wales, these changes have been reflected in recent health care policy, notably the new General Medical Services contract, with its proposal that in future patients are registered with practices rather than a particular physician. ${ }^{11}$

Although personal continuity in general practice appears to be threatened, there have been no recent national or international surveys of general practitioners (GPs) about their views on and attitudes toward the provision of continuity of care in general practice. We therefore surveyed GPs in 3 different health care systems. In England and Wales and the Netherlands, GPs deliver first-contact care and act as gatekeepers to secondary care; in the United States family physicians deliver first contact care but patients can refer themselves to specialists.12,13 In this article the term GP is used to cover both GPs in the United Kingdom and the Netherlands and family physicians in the United States. The aim of the study was to explore (1) the value GPs in the 3 countries place on the various types of continuity of care, (2) whether different groups of GPs within each country differed in the value they placed on personal continuity of care, and (3) the extent to which GPs believed that personal continuity could be substituted for by other means of providing continuity of care.

\section{METHODS}

A random sample of GPs was drawn from 3 national databases in England and Wales (Organisation Codes Service of the NHS Information Authority), the Netherlands (Netherlands Institute for Primary Care Research), and the United States (active members of the American Academy of Family Physicians). The sample size (1,000 for England and Wales and United States; 700 for the Netherlands) was calculated to allow estimation of the proportion of GPs in each country agree-
Table 1. Statements Combined to Form a Scale of Attitude Toward Personal Continuity

1. Being able to see the same patients over time is one of the most rewarding aspects of general practice

2. Being able to see the same patients over time contributes to the development of my professional knowledge

3. If recording and transfer of patient information is good, there is no need for most patients to see the same GP consistently (reverse coded)

4. If different health professionals work together to provide coordinated and consistent care, there is no need for most patients to see the same GP consistently (reverse coded)

5. Ideally patients should have most of their care provided by the same GP

$\mathrm{GP}=$ general practitioners in the United Kingdom and Netherlands and family physicians in the United States.

ing with any given statement to within plus or minus $3 \%$, assuming that about $50 \%$ of GPs agree (95\% confidence interval $[\mathrm{CI}]$ ). The questionnaire design and sampling strategy were designed to maximize the response rate. ${ }^{14}$ The questionnaire was pilot tested on a sample of GPs from the 3 study countries, which resulted in modifications that reflected the differences in the delivery and organization of primary care in England and Wales, the Netherlands, and the United States. ${ }^{12,13}$ Questionnaires were posted in spring 2003 (England and Wales, and United States) and summer 2003 (Netherlands). Those not responding were sent the questionnaire up to 2 more times at intervals of 4 weeks.

The self-administered structured questionnaire (as displayed in the Supplemental Appendix, available online-only at http://www.annfammed.org/cgi/ content/full/3/4/353/DC1) was developed from previous survey instruments, ${ }^{15,16}$ and included statements covering 3 main areas: the importance of different types of continuity of care $e_{i}$ the extent to which GPs believed they were able to provide the different types of continuity in their day-to-day practice; and GPs' attitudes toward continuity, including whether personal continuity could be substituted by informational and management continuity. Responders indicated the extent to which they agreed with each of the statements using a 5 -point Likert-type scale, where $1=$ strongly disagree and 5 = strongly agree. Scores on 5 of the attitude statements were combined to produce a single score reflecting how much GPs valued personal continuity of care (the 5 statements are shown in Table 1). Factor analysis indicated that these statements formed a unidimensional scale, with good internal consistency $(\alpha=0.78)$. The scale score correlated highly with the overall rating of the importance of personal continuity $(P<.001)$.

Data were analyzed using SPSS 11.0 for Windows. Descriptive and simple summary statistics were 
calculated. We hypothesized that attitudes toward personal continuity of care in each health care system would be influenced by the following demographic variables: practice list size, whether practice has a personal list system, GP working fullor part-time, GP age, and GP sex. ${ }^{17}$ Multiple linear regression was used to explore this hypothesis. Differences between countries in attitudes toward, and provision of, continuity were tested using 1-way analysis of variance (ANOVA) and the Tukey test. Participants were asked 1 open question about continuity of care in modern general practice. These responses were inductively grouped into categories by TS and CT.

\section{RESULTS}

The response rates were England and Wales $60 \%$ (568 of 946), Netherlands 76\% (502 of 660), and United States $47 \%$ (453 of 963). The representativeness of the samples was determined for age and sex. The samples were representative of the populations from which they were drawn for age (all 3 countries) and sex (England and Wales and United States only; the Netherlands sample had significantly more female GPs respond, $30.5 \%$ vs $26 \%$ in the study population, $P=.022$ ). Table 2 shows the demographic characteristics of the responders.

The GPs in all 3 countries believed strongly that personal continuity of care remained an important aspect of good-quality care to their patients (Table 3). In their free-text comments, GPs from all 3 countries emphasized the importance of being able to provide personal continuity of care. It was believed to be preferred by both patient and GP and a source of satisfaction for both parties:

- "People prefer to visit the same dentist and hairdresser, why should they be maneuvered into seeing any doctor? Medicine is personal. Patients do not want to be examined by a series of endless strangers" (GP 787, England and Wales).

- "The loss of continuity relationships and the loss of time to tend to them is one of the major reasons for discontent between doctors and patients" (GP 179, US).
The GPs in all 3 countries believed that they were currently able to provide all 3 types of continuity of care, although GPs in England and Wales were least positive about the provision of informational and management continuity across the primary-secondary care divide (Table 4). This lack of continuity was highlighted in the free-text comments, where GPs in England and Wales emphasized the need to improve on the current poor transfer of information and patient management across the primary-secondary care interface:

- "Lack of communication between secondary care and primary care continues (as always) to be an outstanding problem" (GP 48, UK).

The GPs were asked whether personal continuity of care could be substituted for by informational 
Table 3. Perceived Importance of the Types of Continuity of Care in Relation to Quality of Patient Care

\begin{tabular}{|c|c|c|c|c|}
\hline Statement & $\begin{array}{l}\text { England \& Wales } \\
\text { Mean (SD) }\end{array}$ & $\begin{array}{l}\text { Netherlands } \\
\text { Mean (SD) }\end{array}$ & $\begin{array}{l}\text { United States } \\
\text { Mean (SD) }\end{array}$ & $\begin{array}{c}P \\
\text { Value* }\end{array}$ \\
\hline $\begin{array}{l}\text { Building up relationships over time with the patients that you see } \\
\text { (personal continuity) }\end{array}$ & $4.60(0.61) a$ & $4.53(0.65)_{a}$ & $4.77(0.48)$ & $<.001$ \\
\hline Good recording and transfer of information (informational continuity) & $4.66(0.56)_{a}$ & $4.49(0.62)_{b}$ & $4.59(0.59)_{a, b}$ & $<.001$ \\
\hline $\begin{array}{l}\text { Different health professionals working together with you to provide } \\
\text { coordinated and consistent care (management continuity) }\end{array}$ & $4.44(0.68)_{a}$ & $4.17(0.7)$ & $4.52(0.61)_{a}$ & $<.001$ \\
\hline $\begin{array}{l}\text { Providing care and management for a wide range of health problems } \\
\text { within your practice (management continuity) }\end{array}$ & $4.23(0.76)$ & $3.92(0.81)$ & $4.45(0.69)$ & $<.001$ \\
\hline
\end{tabular}

Table 4. Extent to Which GPs Felt Able to Provide Different Types of Continuity of Care to Their Patients in Their Day-to-Day Practice

\begin{tabular}{|c|c|c|c|c|}
\hline Statement & $\begin{array}{l}\text { England \& Wales } \\
\text { Mean (SD) }\end{array}$ & $\begin{array}{l}\text { Netherlands } \\
\text { Mean (SD) }\end{array}$ & $\begin{array}{l}\text { United States } \\
\text { Mean (SD) }\end{array}$ & $\begin{array}{c}P \\
\text { Value* }\end{array}$ \\
\hline $\begin{array}{l}\text { I have the opportunity to build up relationships over time with } \\
\text { many of the patients I see }\end{array}$ & $4.31(0.78)_{a}$ & $4.33(0.63)_{a}$ & $4.32(0.88)_{a}$ & .89 \\
\hline $\begin{array}{l}\text { There is very good recording and transfer of patient information } \\
\text { within my practice }\end{array}$ & $4.03(0.75)_{a, b}$ & $4.14(0.69)_{a}$ & $3.87(0.85)_{b}$ & $<.001$ \\
\hline $\begin{array}{l}\text { There is very good recording and transfer of patient information from } \\
\text { health professionals/service providers outside the practice, to my } \\
\text { practice }\end{array}$ & $2.89(0.95)$ & $3.37(0.8)_{a}$ & $3.21(0.89)_{a}$ & $<.001$ \\
\hline $\begin{array}{l}\text { The physicians, nurses and other health professionals in my practice } \\
\text { (employed and attached staff) work to-gether to provide coordinated } \\
\text { and consistent care }\end{array}$ & $4.14(0.73)_{a}$ & $4.23(0.66)_{a}$ & $4.13(0.77)_{\mathrm{a}}$ & .08 \\
\hline $\begin{array}{l}\text { Health professionals/service providers outside the practice (eg, } \\
\text { hospitals) work with my practice to provide coordinated and } \\
\text { consistent care }\end{array}$ & $2.98(0.90)_{a}$ & $3.06(0.85)_{a}$ & $3.41(0.85)$ & $<.001$ \\
\hline $\begin{array}{l}\text { The patients I see can have a wide range of health problems } \\
\text { managed within my practice }\end{array}$ & $4.34(0.69)_{a}$ & $4.19(0.65)_{a}$ & $4.50(0.70)$ & $<.001$ \\
\hline \multicolumn{5}{|l|}{ Score: 1 = strongly disagree; 5 = strongly agree. } \\
\hline \multicolumn{5}{|l|}{ * Significance of differences between scores by country (1-way analysis of variance). } \\
\hline
\end{tabular}

and management continuity (Table 5). Most GPs in each country did not agree with the idea that personal continuity was not required if informational and management continuity of care were in place, especially the US GPs. The variance around this attitude was relatively wide, however particularly in the United Kingdom and the Netherlands, suggesting a range of views on this issue.

Overall, the quantitative data indicated that US GPs held the strongest views on the value of personal continuity. Free-text comments from US GPs highlighted the fact that the health insurance market in some cases required patients to change their physician every year, which was detrimental to providing personal continuity:

- "Patients are frustrated when their insurance dictates they seek care elsewhere. I have heard comments many times - 'I just find a doctor I like and who listens, and they [insurance company] make me change ${ }^{\prime \prime \prime}$ (GP 565, US).

Multiple linear regression was used to explore the hypothesis that attitudes toward personal continuity within each health care system, as measured by the personal continuity attitude scale, would be related to the following demographic variables: practice list size, whether practice has personal list system, GP working full- or part-time, GP age, and GP sex (Table 6). In England and Wales, GP sex and personal list were significant predictors of attitude to personal continuity, with female GPs and GPs from practices with personal list systems placing a higher value on personal continuity compared with male GPs and those who did not operate personal lists. In the United States, age of GP was a significant predictor, with GPs younger than 35 
Table 5. Extent to Which GPs Agree That the Provision of Personal Continuity of Care to Their Patients Can Be Substituted for by Other Types of Continuity

\begin{tabular}{|c|c|c|c|c|}
\hline Statement & $\begin{array}{c}\text { England \& Wales } \\
\text { Mean (SD) }\end{array}$ & $\begin{array}{l}\text { Netherlands } \\
\text { Mean (SD) }\end{array}$ & $\begin{array}{l}\text { United States } \\
\text { Mean (SD) }\end{array}$ & $\begin{array}{c}P \\
\text { Value* }\end{array}$ \\
\hline $\begin{array}{l}\text { If recording and transfer of patient information is good, there is no } \\
\text { need for most patients to consistently see the same physician }\end{array}$ & $2.79(1.14)_{a}$ & $2.93(1.14)_{a}$ & $1.77(0.82)$ & $<.001$ \\
\hline $\begin{array}{l}\text { If different health professionals work together to provide coordinated } \\
\text { and consistent care, there is no need for most patients to consis- } \\
\text { tently see the same physician }\end{array}$ & $2.82(1.10)_{\mathrm{a}}$ & $2.88(1.08)_{a}$ & $1.80(0.82)$ & $<.001$ \\
\hline \multicolumn{5}{|l|}{ Score: 1 = strongly disagree; $5=$ strongly agree. } \\
\hline \multicolumn{5}{|c|}{ * Significance of differences between scores by country (1-way analysis of variance). } \\
\hline \multicolumn{5}{|c|}{$\begin{array}{l}\text { a, b: Scores on the same row that share the same subscript do not differ significantly. All other differences between scores on the same row are statistically significant at } \\
P<.001 \text { according to the Tukey test comparison. }\end{array}$} \\
\hline
\end{tabular}

years indicating a more positive attitude than those older than 50 years. In the Netherlands, full-time and part-time status was a significant predictor, with fulltime GPs having more positive attitudes to personal continuity. Even so, physicians' personal and practice characteristics explained only a small part of the variance in attitudes toward the provision of personal continuity of care (England and Wales $r^{2}=0.04$, United States $r^{2}=0.01$, Netherlands $\left.r^{2}=0.04\right)$.

\section{DISCUSSION}

This international survey shows that GPs from 3 different health care systems view the provision of personal, informational, and management continuity of care as important aspects of primary medical care. Its findings are consistent with and update earlier national surveys of GPs. ${ }^{15,16}$

The response rate compared favorably with other recent national surveys of GPs, ${ }^{14}$ and respondents were representative of the populations from which they were drawn. The variable response rate between countries, however, meant that it was difficult to interpret the importance of differences in intercountry scores on the various types of continuity of care. A further limitation is that the results on the contribution of continuity to quality of care are highly skewed positively, as is the extent to which GPs perceive they provide personal continuity in their practice, which raises the possibility of a social desirability bias in the responses. This bias may have partly obscured any true associations between GP characteristics and views on the importance of continuity.

Personal continuity of care, defined as an ongoing therapeutic relationship between a patient and 1 or more health care providers, ${ }^{3}$ was rated as highly important by GPs from all 3 health systems. GPs believed that personal continuity was a key aspect of their work and that personal continuity could not be compensated for by better informational or management continu- ity. These findings are consistent with those of recent surveys of both GPs and GPs in training, which also emphasize the value GPs place on personal continuity of care. ${ }^{18}$ Interestingly, personal continuity of care was valued most by US GPs, even though this group of physicians noted, in their qualitative comments, the difficulties forced discontinuity of care (health care insurer changing patient's physician every year) places on the provision of personal continuity in the United States. ${ }^{19}$ Patients also value personal continuity. Except for patients with chronic diseases, however patients appear to be unwilling, in the United States at least, to either spend more time or money to maintain continuity with an individual physician. ${ }^{6,20}$ In addition, health care policy makers place a relatively low priority on personal continuity when compared with other features of primary health care provision, such as access to health care. ${ }^{21}$ There is a very real risk that personal continuity of care between patients and physicians may be soon be a thing of the past ${ }^{9,10}$ unless policy makers take account of the preferences of patients and physicians when redesigning health care systems.

The demographic characteristics of physicians that influence attitudes toward the provision of personal continuity of care have hitherto been the subject of limited research. Our findings for England and Wales that female sex of GP and presence of a personal list were predictors of more positive attitudes to personal continuity are consistent with research identifying factors that influence whether patients see their usual GP. ${ }^{17}$ Although we were able to identify characteristics that influence attitudes within a given health care system, physicians' personal and practice characteristics explained only a small part of the overall variance in personal continuity scores. GPs appear to value personal continuity of care, irrespective of health care setting or demographic characteristics.

Even in strikingly different health care systems with different patient expectations and cultural influences, GPs place a high value on maintaining the 
patient-physician relationship through the provision of personal continuity. Further international qualitative research is needed to explore the reported differences

Table 6. Regression of Attitude Toward Personal Continuity on Physicians' Personal and Practice Characteristics

\begin{tabular}{|c|c|c|c|c|}
\hline $\begin{array}{l}\text { Characteristic } \\
\text { by Country }\end{array}$ & $\begin{array}{l}\text { Mean } \\
\text { Continuity } \\
\text { Score by } \\
\text { Group* }\end{array}$ & $\begin{array}{l}\text { Regression } \\
\text { Coefficient }\end{array}$ & $\begin{array}{l}\text { Standard } \\
\text { Error }\end{array}$ & $\begin{array}{c}P \\
\text { Value }\end{array}$ \\
\hline \multicolumn{5}{|c|}{$\begin{array}{l}\text { England \& Wales } \\
\qquad\left(r^{2}=0.04\right)\end{array}$} \\
\hline Age, years & & 0.208 & 0.242 & .39 \\
\hline$<35$ & 18.32 & & & \\
\hline $35-50:$ & 18.64 & & & \\
\hline $50+$ & 18.78 & & & \\
\hline Sex & & -0.696 & 0.340 & .04 \\
\hline Male: & 18.45 & & & \\
\hline Female & 19.03 & & & \\
\hline Full/part time & 18.56 & 0.152 & 0.359 & .67 \\
\hline Full & 18.91 & & & \\
\hline \multicolumn{5}{|l|}{ Part } \\
\hline List size & & 0.208 & 0.316 & .51 \\
\hline$<6000$ & 18.57 & & & \\
\hline$>6000$ & 18.70 & & & \\
\hline \multicolumn{5}{|l|}{$\begin{array}{l}\text { United States } \\
\left(r^{2}=0.01\right)\end{array}$} \\
\hline \multicolumn{5}{|l|}{ Age, years } \\
\hline$<35$ & 22.40 & -0.396 & 0.191 & .04 \\
\hline $35-50$ & 22.05 & & & \\
\hline $50+$ & 21.59 & & & \\
\hline Sex & & -0.088 & 0.265 & .74 \\
\hline Male & 21.85 & & & \\
\hline Female & 22.17 & & & \\
\hline Full/part time & & 0.064 & 0.283 & .82 \\
\hline Full & 21.93 & & & \\
\hline Part: & 22.05 & & & \\
\hline List size & & -.0116 & 0.239 & .63 \\
\hline$<6000$ & 22.04 & & & \\
\hline$>6000$ & 21.89 & & & \\
\hline \multicolumn{5}{|l|}{$\begin{array}{l}\text { Netherlands } \\
\left(r^{2}=0.04\right)\end{array}$} \\
\hline Age, years & & 0.274 & 0.258 & .29 \\
\hline$<35$ & 19.18 & & & \\
\hline $35-50$ & 18.33 & & & \\
\hline $50+$ & 19.07 & & & \\
\hline Sex & & -0.522 & 0.360 & .15 \\
\hline Male & 18.70 & & & \\
\hline Female & 18.59 & & & \\
\hline Full/part time & & -0.998 & 0.341 & .004 \\
\hline Full & 19.12 & & & \\
\hline Part & 18.14 & & & \\
\hline List size & & -0.618 & 0.364 & .09 \\
\hline$<6000$ & 18.80 & & & \\
\hline$>6000$ & 18.09 & & & \\
\hline Personal list & & -0.326 & 0.320 & .31 \\
\hline Yes & 18.85 & & & \\
\hline No & 18.31 & & & \\
\hline
\end{tabular}

in the value GPs place on the 3 types of continuity of care and to explain the findings in terms of the financial, organizational, and cultural aspects of different health care systems. Controlled before and after studies that determine the true impact of health care system reorganizations on measures of continuity of care are also required.

To read or post commentaries in response to this article, see it online at http://www.annfammed. org/cgi/content/full/3/4/353.

Key words: Continuity of care; physician-patient relations

Submitted October 12, 2004; submitted, revised, January 17, 2005; accepted February 23, 2005.

A version of this paper, "Continuity of care-is the personal doctor still important? An international survey of general practitioners in England and Wales, Netherlands and United States," was presented at the SAPC 33rd Annual Scientific Meeting, Glasgow, UK 15th July 2004.

Funding support: The England and Wales survey was supported by a small project grant from the former Department of General Practice and Primary Health Care, University of Leicester.

Acknowledgments: We thank the general practitioners/family physicians from England and Wales, United States and the Netherlands who participated in this research. We thank the Organisation Codes Service of the NHS Information Authority for permission to use their database.

\section{References}

1. Freeman GK, Olesen F, Hjortdahl P. Continuity of care: an essential element of modern general practice? Fam Pract. 2003;20:623-627.

2. National Coordinating Centre for Service Delivery and Organisation. Continuity of Care: Report of a Scoping Exercise for the National Coordinating Centre for Service Delivery and Organisation. 2000. Available at: http://www.sdo.Ishtm.ac.uk/continuityofcare.htm.

3. Gray DP, Evans P, Sweeney K, et al. Towards a theory of continuity of care. J R Soc Med. 2003;96:160-166.

4. Haggerty JL, Reid RJ, Freeman GK, et al. Continuity of care: a multidisciplinary review. BMJ. 2003;327:1219-1221.

5. Kearley KE, Freeman GK, Heath A. An exploration of the value of the personal doctor-patient relationship in general practice. Br J Gen Pract. 2001;51:712-718.

6. Pereira AG, Pearson SD. Patient attitudes toward continuity of care. Arch Intern Med. 2003;163:909-912.

7. Nutting PA, Goodwin MA, Flocke SA, Zyzanski SJ, Stange KC. Continuity of primary care: to whom does it matter and when? Ann Fam Med. 2003;1:149-155. 
8. Schers $\mathrm{H}$, Webster $\mathrm{S}$, van den Hoogen $\mathrm{H}$, et al. Continuity of care in general practice: a survey of patients' views. $\mathrm{Br} J$ Gen Pract. 2002;52:459-462.

9. Hjortdahl P. Continuity of care-going out of style? Br J Gen Pract. 2001;51:699-700.

10. Baker R. Will the future GP remain a personal doctor? Br J Gen Pract. 1997;47:831-833.

11. General Practitioners Committee and the NHS Confederation. Investing in General Practice: The New General Medical Services Contract. London: British Medical Association; 2003.

12. Campbell JL, Mendive J, Timmermans A. Primary care and general practice in Europe: West and south. In: Oxford Textbook of Primary Medical Care. Jones R, Britten N, Culpepper L, et al, eds. Oxford, UK: Oxford University Press; 2004:65-70.

13. Ostergaard DJ KN, Henderson D. Primary care and general practice in North America. In: Oxford Textbook of Primary Medical Care. Jones R, Britten N, Culpepper L, et al, eds. Oxford, UK: Oxford University Press; 2004:84-88.

14. Barclay S, Todd C, Finlay I, Grande G, Wyatt P. Not another questionnaire! Maximizing the response rate, predicting non-response and assessing non-response bias in postal questionnaire studies of GPs. Fam Pract. 2002; 19:105-111.
15. Freeman G. Priority given by doctors to continuity of care. J R Coll Gen Pract. 1985;35:423-426.

16. Hjortdahl P. Ideology and reality of continuity of care. Fam Med. 1990;22:361-364.

17. Guthrie B. Continuity in UK general practice: a multilevel model of patient, doctor and practice factors associated with patients seeing their usual doctor. Fam Pract. 2002; 19:496-499.

18. Schers $H$, van de Ven $C$, van den Hoogen $H$, Grol R, van den Bosch W. Family medicine trainees still value continuity of care. Fam Med. 2004;36:51-54

19. Flocke SA, Stange KC, Zyzanski SJ. The impact of insurance type and forced discontinuity on the delivery of primary care. J Fam Pract. 1997;45:129-135.

20. Love MM, Mainous AG, 3rd, Talbert JC, Hager GL. Continuity of care and the physician-patient relationship: the importance of continuity for adult patients with asthma. J Fam Pract. 2000;49:998-1004.

21. Salisbury C. Does advanced access work for patients and practices? $\mathrm{Br}$ J Gen Pract. 2004;54:330-331. 